\title{
ICONICITY ADAPTATION: \\ AN ANALYSIS OF ONOMATOPOEIAS IN FINANCE SMURFS COMIC AND ITS INDONESIAN TRANSLATION SMURF BENDAHARA
}

\author{
Ailsa Agatha Santoso, Nina Setyaningsih \\ ailsa.agatha18@gmail.com \\ Universitas Dian Nuswantoro
}

\begin{abstract}
Onomatopoeia is one example of iconic signs influenced by the culture of the origin of the speakers. Translating an onomatopoeic word will need more than just a dictionary, but also culture and linguistic understanding of both source and target languages. Dealing with this issue, this research attempts to investigate how the onomatopoeias featured in the Finance Smurfs comic is translated into Indonesian. The data were obtained from Finance Smurfs comic and its translated version. Using articulatory phonetics to describe 47 onomatopoeias found in the comic, 43 are classified as iconic in both SL and TL, while 4 of them are not iconic. In addition, although the forms of onomatopoeias in source and target language are different their meanings are maintained based on the context.
\end{abstract}

Keywords: comic, Finance Smurfs, iconicity, onomatopoeia, translation

Iconicity is related to an object and its resemblance. It can be found not only in photographs, but also expression, graphics, figures, even metaphors. In language, to consider whether an object is iconic or not, there are several facts that can make them relate each other. Certain sound sometimes can have meaning. This is called sound symbolism. It is a relation between sound and its specific meaning. Sounds can be determined as iconic if the production symbolizes the words itself.

Onomatopoeia is a word or an object named after the sound it produces. Onomatopoeias are also influenced by the culture of the origin of the speakers. For example, the equivalence of onomatopoeic sound of a pig in Indonesian 'ngok-ngok' [NOk NOk] is 'oink-oink' [OINk OINk] in English. The form of onomatopoeic sounds of animal has different structure in different language since different languages have different characteristics. Their phonological systems are also completely different. Many onomatopoeic words are arbitrary in nature. For instance, the sound of a gun is 'bang' $[\mathrm{b}\{\mathrm{N}]$ in English, while in Indonesian it is perceived as 
'dor' [dOr]. However, despite their arbitrariness, some onomatopoeic words are iconic. As a case in point, it can be found in the sound of a gecko in Indonesian. The Indonesian word for gecko is 'tokek', derived from the sound of the animal.

In dealing with translation, one of the challenges in conducting an analysis of a translation work is when the source language and the target language (henceforth SL and TL respectively) have a completely different structure or form, including sounds, words, phases, clauses sentences, and so on. Translation is basically transforming between two languages. Translating a language is not only changing SL into TL but also transferring ideas. When a translator translates an onomatopoeic word he or she will need not only a dictionary, but also culture and linguistic understanding of both SL and TL.

Onomatopoeias are often found in comics. In translating comic series, the translator is expected to master more than just the language but also the culture to know whether it is appropriate to read and acceptable to the readers. As an illustration, the following figure demonstrates an onomatopoeic sound in a Smurf comic:
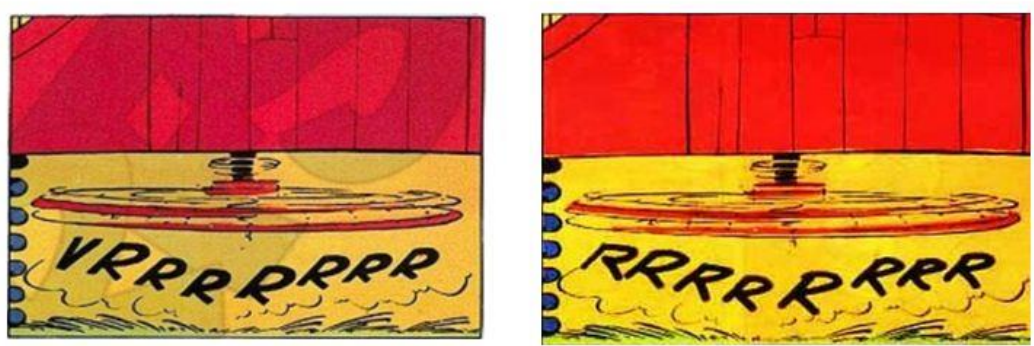

Figure 1: A panel from page 11 of Astro Smurfs' Rocket Machine (Astro Smurfs, 1970)

In Figure 1, the comic will somehow lose its meaning if the sound of the machine is not given an onomatopoeic sound. The onomatopoeia eases the readers in imagining how the machine sounds like. The figure presents the sound of a rocket machine in SL as vrrrr translated into TL rrrr. Hence, the way certain sound is perceived in different languages, and how it influences the way the translator translates the onomatopoeia are some of the reasons why the translation of onomatopoeia in the comic is of an important issue. 
Ailsa Agatha Santoso, Nina Setyaningsih, Iconicity Adaptation: An Analysis of Onomatopoeias in Finance Smurfs Comic and Its Indonesian Translation Smurf Bendahara

Therefore, based on the phenomenon previously explained, this research will investigate the Smurf comic entitled Finance Smurfs and its Indonesian translation Smurfs Bendahara. The research aims to analyze whether or not the translation of onomatopoeic words in Finance Smurfs comic still maintains the iconicity.

\section{LITERATURE REVIEWS}

There are previous researches which analyze onomatopoeic words. The first is an analysis of onomatopoeia in Garfield comic (Eliza, 2011). This paper analyzes the onomatopoeia of one particular language (English). From the 15 samples of data of onomatopoeic words, 10 of them are secondary, and 5 are primary onomatopoeic words. The research also identifies two kinds of meaning namely lexical and contextual meaning. The research concludes that the primary is the imitation of the sound of an object and the secondary is the imitation of the combined sounds of an object and its movement. Another research is on the onomatopoeic words in Indonesian comic Baru Klinting (Najichah, 2018). This research analyzes the structures and meaning of onomatopoeia in the comic. The findings of this research show that there are there are three types of onomatopoeia structure, namely monosyllable, bisyllable, and multisyllable. The meanings of these onomatopoeic words are classified into onomatopoeia of circumstance, action, sound imitation, and character's emotional state.

Each of the previous studies above examines the onomatopoeia of one language in the data, and mainly concerns on the types and meanings of onomatopoeia found in the respective language. This research attempts to focus on analyzing a different comic book, Finance Smurfs, and its Indonesian translation. Moreover, as onomatopoeia may be arbitrary or iconic, this research also explores how onomatopoeic words in the comic might have a possibility of being either iconic or non-iconic by looking at how the sounds of English and Indonesian onomatopoeias in the comic are produced. 


\section{Translation}

An activity which aims at delivering meanings of any discourse from one origin language into second language is called translation. Machali (2000) says that translation deals with meaning rendered from SL into TL. Hartono (2009) states that translation is a transfer process which aims at the transformation of a written SL text into an optimally equivalent TL text, and which requires the syntactic, the semantic, and the pragmatic understanding and analytical processing of the source text. Thus, it can be said that the main focus of translation deals with the delivering of meaning from SL into TL.

When translating, there are shifts between the source and the target language. Machali (2000) calls it 'rank shift'. Shift deals with some changes occurring in a translation process. It also occurs when there is no formal correspondence to the syntactic item to be translated. Thus, it can inferred that these shifts can also specify which item is iconic and which one is not.

\section{Iconicity}

Torop (2008: 256) states that "translation semiotics itself can be regarded as a discipline that deals with mediation processes between various sign system, and, on the macro level, with culture as a translation mechanism." According to F. de Saussure (1916), "meaning in semiotic systems is expressed by signs, which have a particular form, called signifier, and some meaning that the signifier conveys, called the signified". In contrast, in the framework of Peirce's semiotic typology, sign has been classified into icon, index, and symbol (Nöth (2001). This triad of signs is defined according to the creation of the relation between the sign vehicle and its referential object. Portraits and onomatopoeia are examples of classifications of iconic images, meaning that one can, by simply looking at the icon, get information about its object (Dofs, 2008). 
Ailsa Agatha Santoso, Nina Setyaningsih, Iconicity Adaptation: An Analysis of Onomatopoeias in Finance Smurfs Comic and Its Indonesian Translation Smurf Bendahara

\section{Onomatopoeia}

Onomatopoeia is the representation or imitation in language of sounds from the natural world, rendered according to a language's phonetic inventory, phonological rules, and socio-historical practices (Guynes, 2014). Onomatopoeias may come from the sound of an object, animal, or action. Onomatopoeia is the representation or imitation in sound of language from the natural world, rendered according to a language's phonetic inventory, phonological rules, and socio-historical practices. For example, the sounds [i] and [e] advise something small and high, the sounds [a], [u], and [o] suggest something great, low, and deep, and the sound [r] expresses something that vibrates (Keraf, 1997).

Onomatopoeia also deals with the relationship between sound and meaning. The idea of sounds having meaning in themselves is called sound symbolism (Dofs, 2008). Hinton et al. (1994) arranges scale the level relation between sound and meaning as follows:

1. Corporeal sound symbolism, specific intonation patterns used to reveal the internal condition of the speaker emotionally and physically. This category includes sounds that are symptomatic unintentional, such as hiccough, sound of feeling, interjection, and sound that related to the emotional and physical condition.

2. Imitative sound symbolism represents onomatopoeic words and phrases in nature and environment, such as bang, knock-knock bow-wow. In the representation of sounds and movements that are repeated, reduplication is often used, such as the sound ding-dong.

3. Synesthetic sound symbolism means using sound to symbolize the non-acoustic phenomena, such as movement, size and shape. For example, many languages in the world show to take advantage of the relationship between the small size of the vowel [i], and the large size of the vowel [a]. 
4. Conventional sound symbolism is analogical on phoneme associations a certain groups with particular meaning. These categories are arbitrary and conventional. For example in English, gl- prefix in the word glitter, glow, glisten, glimmer, is connected with the meaning of the light. This case is not found in languages that do not have prefix consonant $g l$-. Therefore, this case is language-specific, and this phenomenon is commonly called phonestemic.

\section{Articulatory Phonetics}

Articulatory phonetics concerns with the movement of various parts of the vocal tract during speech. Using this branch of phonetics, sounds can be broken down into two categories, namely consonant and vowel.

\section{English and Indonesian Consonant Sounds}

Consonant sounds are produced based on their voicing, place of articulation, and manner of articulation. The consonant sounds in English and Indonesian languages are described in the following charts:

Table 1. English Consonants (Meyer, 2009)

\begin{tabular}{|c|c|c|c|c|c|c|c|}
\hline & Bllablal & Lablodental & Interdental & Alveolar & Palatal & Velar & Glottal \\
\hline \multicolumn{8}{|l|}{ Stop (oral) } \\
\hline voiceless & $\mathrm{p}$ & & & $\mathrm{t}$ & & $\mathrm{k}$ & $?$ \\
\hline voiced & b & & & d & & $\mathrm{g}$ & \\
\hline Nasal (voiced) & $\mathrm{m}$ & & & $\mathrm{n}$ & & n & \\
\hline \multicolumn{8}{|l|}{ Fricative } \\
\hline voiceless & & $\mathrm{f}$ & $\theta$ & $s$ & s & & $\mathrm{h}$ \\
\hline voiced & & $\mathrm{v}$ & д & $z$ & 3 & & \\
\hline \multicolumn{8}{|l|}{ Affricate } \\
\hline voiceless & & & & & ts & & \\
\hline voiced & & & & & dz & & \\
\hline \multicolumn{8}{|l|}{ Glide } \\
\hline voiceless & M & & & & & м & \\
\hline voiced & w & & & & j & w & \\
\hline \multicolumn{8}{|l|}{ Liquid (voiced) } \\
\hline (central) & & & & $\mathrm{r}$ & & & \\
\hline (lateral) & & & & 1 & & & \\
\hline
\end{tabular}


Ailsa Agatha Santoso, Nina Setyaningsih, Iconicity Adaptation: An Analysis of Onomatopoeias in Finance Smurfs Comic and Its Indonesian Translation Smurf Bendahara

Table 2. Indonesian Consonants (Bowen, 2005)

\begin{tabular}{|c|c|c|c|c|c|c|c|c|c|}
\hline & \multirow[b]{2}{*}{ MANNER } & \multirow[b]{2}{*}{ VOICING } & \multicolumn{7}{|c|}{ PLACE } \\
\hline & & & Bilabial & Labiodental & Interdental & Alveolar & Palatal & Velar & Glottal \\
\hline \multirow{6}{*}{ 䍘 } & Stop & Voiceless & p & & & $\mathbf{t}$ & t] & k & (?) \\
\hline & \multirow{2}{*}{ Fricative } & Voiced & b & & & d & dै & g & \\
\hline & & Voiceless & & (f) & & $\mathbf{s}$ & & & \\
\hline & & Voiced & & (v) & & (z) & & & \\
\hline & Affricate & Voiceless & & & & & (D) & (x) & (h) \\
\hline & & Voiced & & & & & & & \\
\hline \multirow{4}{*}{ 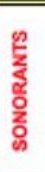 } & Nasal & Voiced & $\mathbf{m}$ & & & $n$ & n & $n$ & \\
\hline & Lateral & Voiced & & & & I & & & \\
\hline & Rhotic & Voiced & & & & $\mathbf{r}$ & & & \\
\hline & Glide & Voiced & $\mathbf{w}$ & & & & i & $\mathbf{w}$ & \\
\hline & & & & & & & & & \\
\hline
\end{tabular}

\section{English and Indonesian Vowel Sounds}

According to Fromkin et al. (2009), vowel sounds are classified based on tongue position, lip rounding, and diphthongs. The vowel sounds in English and Indonesian languages are described in the following charts:

Table 3. Vowel Charts (Meyer, 2009)

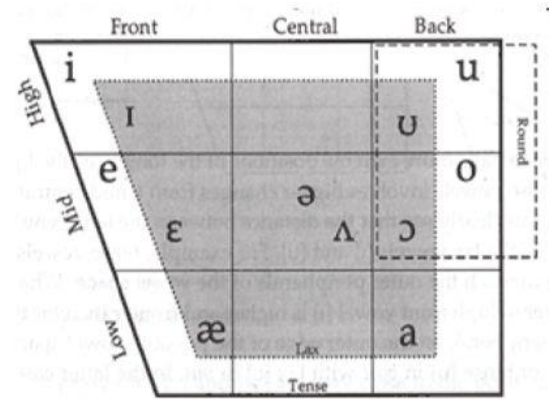

English

\begin{tabular}{|l|c|c|c|}
\cline { 2 - 4 } \multicolumn{1}{c|}{} & Front & Central & Back \\
\hline Close & $\mathrm{i}$ & & $\mathrm{u}$ \\
\hline Mid & $\mathrm{e}$ & $\partial$ & 0 \\
\hline Open & & $\mathrm{a}$ & \\
\hline
\end{tabular}

Indonesian

\section{Diphthong}

A diphthong is a vowel in which there is a noticeable sound change within the

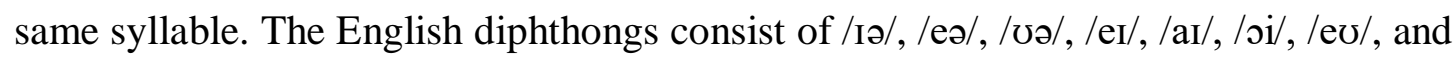
/av/, while Indonesian diphthongs are /ai/, /au/, and /oi/ (Djatmika, 2013). 


\section{METHODS}

This research is a qualitative descriptive one. According to Lambert and Lambert (2012), "a qualitative descriptive approach needs to be the design of choice when a straight forward description of a phenomenon is desired." This research explains the onomatopoeic words and their translated version by describing how those onomatopoeias are produced. The sound production to describe the articulatory phonetic of the onomatopoeic words was conducted by the researchers themselves (Indonesian native speakers majoring in English) and by consulting the dictionaries. The data of this research were taken from Smurfs comic series Finance Smurfs (SL) and its Indonesian translation version Smurf Bendahara (TL). The English comic was downloaded from http://bluebuddies.com, while the Indonesian version was downloaded from http://download-komik-ebook.blogspot.co.id on February 5, 2018. This research focuses on the onomatopoeic words in Finance Smurfs and Smurf Bendahara.

After the data were collected, they were analyzed by following these steps: (1) classifying the English onomatopoeic words and their Indonesian translation, (2) making phonetic transcriptions of each onomatopoeia, (3) determining the meaning of each onomatopoeic word, (4) describing how the onomatopoeic words are produced by using articulatory phonetics, (5) identifying whether the SL and its translation are both iconic or not, and (6) drawing conclusion.

\section{DISCUSSION}

After the data were analyzed, the following findings were found:

Table 4. Findings

\begin{tabular}{cccc}
\hline No & Iconicity & $\boldsymbol{\Sigma}$ & $\boldsymbol{\%}$ \\
\hline 1 & Maintained /iconic & 43 & $92 \%$ \\
2 & Not maintained/non-iconic & 4 & $8 \%$ \\
\hline & TOTAL & 47 & $100 \%$ \\
\hline
\end{tabular}

The English version of Finance Smurf and its Indonesian translation have a total of 44 pages consisting of 434 panels respectively. There are 47 onomatopoeic words 
Ailsa Agatha Santoso, Nina Setyaningsih, Iconicity Adaptation: An Analysis of Onomatopoeias in Finance Smurfs Comic and Its Indonesian Translation Smurf Bendahara

in the comic. Of the 47 data found in Finance Smurf comic, 43 data are qualified as iconic, while 4 data are not. All forms in SL and TL are different but their meanings are still in the same context. The explanation of the findings is as follows.

\section{Iconic}

This section discusses the iconicity adaptation of the onomatopoeias found in Finance Smurfs (SL) and its translation (TL). The translation of the onomatopoeias still maintains the iconicity of the source language version.

\section{Excerpt 1}

Context: A Smurf saves Papa Smurf from an explosion in his laboratory.

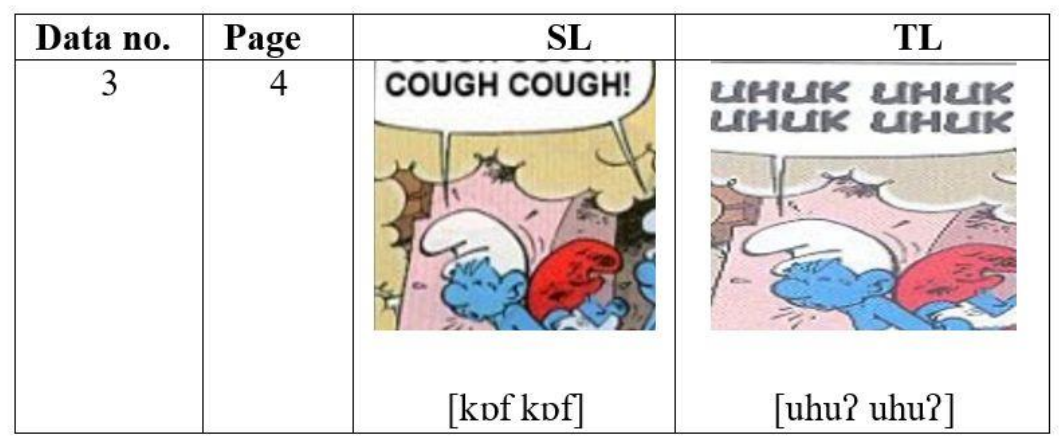

Excerpt 1 shows a Smurf chokes when he accidently inhales gas in the exploded laboratory. The coughing sound is represented as cough cough in SL. The onomatopoeia cough cough is translated into Indonesian uhuk uhuk. These onomatopoeic words mean expelling air from the lungs with a short sound. Both cough cough and uhuk uhuk have similar representation of the sound that expels air suddenly with a sharp sound.

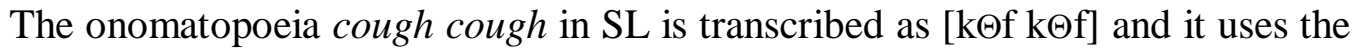
back rounded vowel $[\Theta]$. Meanwhile, in TL the onomatopoeia uhuk-uhuk is transcribed as [uhu? uhu?] and it also uses the back rounded vowel [u]. The vowels $[\Theta]$ and $[u]$ suggest something round and deep. In producing the sounds $[\Theta]$ and $[\mathrm{u}]$, the lips are curved like a little circle, which reflects something that is round and deep. Furthermore, when someone coughs his/her lips will shape like a circle (round) and 
the sound is tense, which also resembles the nature of the back vowels [o] and [u]. The reduplicated sounds also represent the coughing sounds that are usually repeated. From that reason, the onomatopoeic sound in SL and its translation can be considered iconic since they suggest the resemblance of the object.

\section{Excerpt 2}

Context: Chef Smurf rings a bell to inform every Smurf in the village that it is meal time.

\begin{tabular}{|c|c|c|c|}
\hline Data no. & Page & SL & TL \\
\hline 9 & 13 & - MEALTIME! & $B$ \\
\hline & & [dilin dilin] & [klinin klinin] \\
\hline
\end{tabular}

Excerpt 2 shows Chef Smurf jingles a bell that sounds "diling diling" in SL. The sound is translated into "klining klining". The sound "diling diling" [dilin dilin] and "klining klining" [klinin klinin] have the same representation of the sound of a jingling bell. The sound [dilin dilin] uses the high front vowel [i] and the voiced velar nasal consonant [y]. Meanwhile, the sound [klinin klinin] also uses the front vowel [i] and the voiced velar nasal [y]. The high tone [i] suggests a small size, while the voiced velar nasal [y] suggests resonance or vibration. In articulating of the sound [i] the lips are slightly opened, while in [y] the back of the tongue constricts with the velum and vibrates the vocal cord, thus reflecting the resonance. These sounds suggest the small shape of the bell and the clapper that strikes the bell so as to create the jingling sound. Therefore, the SL and translated version of the onomatopoeic sound are both iconic. 
Ailsa Agatha Santoso, Nina Setyaningsih, Iconicity Adaptation: An Analysis of Onomatopoeias in Finance Smurfs Comic and Its Indonesian Translation Smurf Bendahara

\section{Excerpt 3}

Context: Farmer Smurf hears the sound "critch cratch" and finds out that it is Gargamel walking through the woods.

\begin{tabular}{|c|c|c|c|}
\hline Data no. & Page & SL & TL \\
\hline 25 & 27 & [kritt kratt] & [srek srek] \\
\hline
\end{tabular}

In the excerpt above, the sound "critch cratch" in English is translated into "sreek sreek". The onomatopoeia "critch cratch" and its translation "sreek sreek" have affricate $[\mathrm{t} \Sigma]$ and fricative [s] respectively. Both sounds suggest the sound of something rubbed or a friction against a rough surface. They also have the sound $[\mathrm{r}]$ which indicates motion or vibration.

In articulating of the sound [r], the tip of the tongue constricts with alveolar ridge. The tongue also vibrates when pronouncing $[\mathrm{r}]$. Regarding the affricate $[\mathrm{t} \Sigma]$ and fricative [s], these sounds are produced by a constriction of airflow to create friction. The vibration, the friction, and the sound reduplications suggest a repeating fast movement of the onomatopoeic words which describes Gargamel's walk. Therefore, the Indonesian translation of the onomatopoeia "critch cratch" into "sreek sreek" still maintains the iconicity.

\section{Non-iconic}

Although most of the data findings show that the translation of onomatopoeias in Finance Smurfs comic still maintains the iconicity of the SL version, there are onomatopoeias that do not maintain the iconicity. The examples are provided below. 


\section{Excerpt 4}

Context: Azrael, Gargamel's cat, is being hit with a wooden stick by a Smurf.

\begin{tabular}{|c|c|c|c|}
\hline Data no. & Page & SL & TL \\
\hline 38 & 38 & PIF & \\
& & & \\
& & & \\
& & & \\
& & & \\
& & & \\
& & & \\
& &
\end{tabular}

To describe the sound of a light punch or hit in a small range, the sound "pif" in SL is translated into "bletak" in TL. The word "pif" is transcribed as [pif], which contains the high front vowel [I]. Meanwhile, the word "bletak" is transcribed as [bl§tak], containing the low central vowel [a]. Furthermore, [pif] has the voiceless

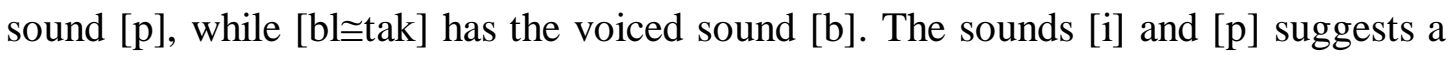
meaning of small or light, while [a] and [b] are the opposite, i.e. they sound heavier. The sound [pif] indicates that the action of Smurf hitting Azrael is done slightly. In contrast, the translation version [bl@tak] indicates that Smurf's action is done harder.

From the description above it can be implied that there is a shift in the translation. In this case, the data demonstrate that the sound symbolism does not hold because the same hitting action is described by using different onomatopoeias with sounds that are mostly different in nature. From this explanation, it can be said that the translation does not maintain the iconicity of the SL. Therefore, the onomatopoeia of the hitting action in this case is considered non-iconic or arbitrary.

\section{Excerpt 5}

Context: Smurf laughs out loud. 
Ailsa Agatha Santoso, Nina Setyaningsih, Iconicity Adaptation: An Analysis of Onomatopoeias in Finance Smurfs Comic and Its Indonesian Translation Smurf Bendahara

\begin{tabular}{|c|c|c|c|}
\hline Data no. & Page & SL & TL \\
\hline 2 & 3 & HA HA HA \\
& & & \\
& & & \\
[hA HAI ha ha ha ha] & [hi hi hi] \\
\hline
\end{tabular}

The above excerpt shows the onomatopoeia of a laughing Smurf. The SL version of the laugh [ha ha ha ha ha] is translated into SL as [hi hi hi]. The SL [ha ha ha ha ha] contains the low central vowel [a], while the TL has the high front vowel [i]. The sound [a] is produced with an open mouth, whereas [i] is produced with stretched lips.

In this data sample, the translation does not maintain the iconicity of the SL. Therefore, in this context the laughing sound is arbitrary since in the comic, a different language has a different way of expressing the same laugh.

\section{CONCLUSION}

After the data were analyzed, it can be concluded that in terms of how the onomatopoeic words are translated into Indonesian (TL) by looking at the way they are articulated and transcribed phonetically, most of these words are iconic both in SL and TL. However, not all onomatopoeic words in the Indonesian version (Smurf Bendahara) still maintain the iconicity of the source language version (Finance Smurfs). Furthermore, there is a shift in terms of the form of the onomatopoeia. Although the forms of onomatopoeia in SL and TL are different, their meanings are maintained based on the context.

In addition, since the phonetic transcription in this research was mainly based on the researchers' sense, it is suggested that future research consult to native speakers of SL and TL. Also, a more comprehensive analysis on the way onomatopoeic words are translated by using certain translation techniques needs to be clarified. 


\section{REFERENCES}

Bowen, Caroline. (2015). Speech Language Therapy. Retrieved on June 4, 2018 from https://www.speech-language-therapy.com/index.php?option=com_content\& view $=$ article $\&$ id $=22 \&$ Itemid $=124$

Djatmika, Unggul. (2013). Contrastive Linguistics \& Error Analysis. Retrieved on June 13, 2018 from https://www.slideshare.net/Djatmika1/contrastingindonesian-english-diphthongs

Eliza, Tiara. (2013). An Analysis of Onomatopoeia in Garfield Comic. Vivid Journal of Language and Literature Vol 2, No 2

Dofs, Elin. (2008). A Comparative Study of English and Swedish Animal Sound. Karlstad: Karlstad University

Fromkin, Victoria, Robert Rodman, and Nina Hyams. (2009). An Introduction to Language. Boston : MA Cengage Wadsworth.

Guynes, S. A. (2014). Four-color sound: a peircean semiotics of comic book onomatopoeia. The Public Journal of Semiotics, 6(1):58-72.

Hartono, Rudi. (2009). Teori Penerjemahan (A Handbook for Translator). Semarang: Cipta Prima Nusantara

Hinton, Leanne, Johanna Nichols, and John J. Ohala. (1994). Sound Symbolism. Cambridge: Cambridge University Press.

http://bluebuddies.com/cgi-bin/ultimatebb.cgi?ubb=get_topic; $f=1 ; t=003265 ; p=0$ [Retrieved on Feb 20 ${ }^{\text {th }}$, 2018]

http://download-komik-ebook.blogspot.co.id/2013/07/komik-smurf-bahasaindonesia.html [Retrieved on Feb 20 ${ }^{\text {th }} .2018$ ]

Keraf, Gorys. (1997). Lingustik Bandingan Tipologis. Jakarta: Gramedia

Lambert, V. A., \& Lambert, C. E. (2012). Qualitative Descriptive Research: An Acceptable Design. Pacific Rim International Journal of Nursing Research, 16(4), 255-256. Retrieved from https://he02.tcithaijo.org/index.php/PRIJNR/article/view/5805

Machali, Rochayah. (2000). Pedoman Bagi Penerjemah. Jakarta: PT. Grasindo

Meyer, Charles F. (2009). Introducing English Linguistics. Boston: Univerrsity of Massachusetts Press. 
Ailsa Agatha Santoso, Nina Setyaningsih, Iconicity Adaptation: An Analysis of Onomatopoeias in Finance Smurfs Comic and Its Indonesian Translation Smurf Bendahara

Najichah, Amalia Fajriyyatin. (2018). Analisis Struktur dan Makna Onomatope dalam Komik Baru Klinting Karya Sapriandy. Jalabahasa Jurnal Ilmiah Kebahasaan. Vol. 14 No. 2 pp1-8

Nöth, Winfried. (2001). Semiotic Foundations of Iconicity in Language and Literature. Sao Paulo: University of Kassel and Catholic University of Sao Paulo. 